\title{
BMJ Open Joint associations of fresh fruit intake and physical activity with glycaemic control among adult patients with diabetes: a cross-sectional study
}

\author{
Jie Wu (D) , ${ }^{1}$ Xin Hong (D) , ${ }^{1}$ Chenchen Wang, ${ }^{1}$ Shengxiang Qi, ${ }^{1}$ Qing Ye, ${ }^{1}$ \\ Zhenzhen Qin, ${ }^{1}$ Hairong Zhou, ${ }^{1}$ Chao Li, ${ }^{1,2}$ Weiwei Wang, ${ }^{1}$ Nan Zhou (1) ${ }^{1}$
}

To cite: Wu J, Hong X, Wang C, et al. Joint associations of fresh fruit intake and physical activity with glycaemic control among adult patients with diabetes: a cross-sectional study. BMJ Open 2022;12:e056776. doi:10.1136/ bmjopen-2021-056776

- Prepublication history and additional supplemental material for this paper are available online. To view these files, please visit the journal online (http://dx.doi.org/10.1136/ bmjopen-2021-056776).

JW and XH contributed equally.

JW and $\mathrm{XH}$ are joint first authors.

Received 25 August 2021 Accepted 07 February 2022

D Check for updates

(C) Author(s) (or their employer(s)) 2022. Re-use permitted under CC BY-NC. No commercial re-use. See rights and permissions. Published by BMJ.

${ }^{1}$ Non-communicable Disease Prevention, Nanjing Municipal Center for Disease Control and Prevention, Nanjing, China

${ }^{2}$ Department of Epidemiology and Biostatistics, Nanjing Medical University, Nanjing, China

Correspondence to

Dr Nan Zhou;

nj_zhounan@126.com

\section{ABSTRACT}

Objective To investigate the joint associations of fresh fruit intake and physical activity with glycaemic control in adult patients with diabetes mellitus (DM).

Design It was an observational study involving adult patients with DM through a face-to-face questionnaire survey, physical measurements and laboratory examinations. Data were analysed by introducing a generalised linear mixed model, and a significant difference was set at $p<0.05$.

Setting Nanjing, Jiangsu, China

Participants A total of 5663 adult patients with DM from the 2017 Nanjing Chronic Disease and Risk Factor Surveillance were recruited.

Results Based on the food frequency questionnaire, fresh fruit intake was classified as 'not eat', '1 99 g/day' and ' $\geq 100 \mathrm{~g} /$ day'. Physical activity level was calculated based on the data of Global Physical Activity Questionnaire and classified into insufficient physical activity $(<600$ MET-min/ week) and sufficient physical activity ( $\geq 600$ MET-min/ week). The likelihood of glycaemic control in adult patients with DM with fresh fruit intake $\geq 100 \mathrm{~g} /$ day was $37.8 \%$ (OR: $1.378 ; 95 \% \mathrm{Cl}: 1.209$ to 1.571 ) higher than those with fresh fruit intake $<100 \mathrm{~g} /$ day, which was $26 \%$ (OR: 1.260; $95 \% \mathrm{Cl}: 1.124$ to 1.412 ) higher in adult patients with DM with sufficient physical activity than those with insufficient physical activity. Adult patients with DM with fresh fruit intake $\geq 100 \mathrm{~g} /$ day and sufficient physical activity presented the greatest likelihood of glycaemic control (OR: 1.758; $95 \% \mathrm{Cl}: 1.471$ to 2.102) compared with those with both fresh fruit intake $<100 \mathrm{~g} /$ day and insufficient physical activity.

Conclusions Fresh fruit intake $\geq 100 \mathrm{~g} /$ day combined with sufficient physical activity is associated with a significantly higher likelihood of glycaemic control in adult patients with DM.

\section{INTRODUCTION}

Diabetes mellitus (DM) is one of the fastest growing health issues in the $21^{\text {st }}$ century, the case number of which in adults has been tripled over the past 20 years. According to the latest report of the International Diabetes Federation (2019), the global prevalence of $\mathrm{DM}$ in adults is $9.3 \%$, involving 463 million
Strengths and limitations of this study

- This study highlights the joint association of fresh fruit intake and physical activity with glycaemic control in adult patients with diabetes mellitus.

- This study analyses high-quality data from the population-based representative sample using a generalised linear mixed model, which avoids the clustering of data.

- This study does not assess glycaemic control using the representative indicator haemoglobin A1C.

- The cross-sectional study limits the assessment of causality.

affected adults. ${ }^{1}$ DM is a significant risk of morbidity and premature mortality for blindness, cardiovascular, kidney and nerve diseases. ${ }^{2-4}$ Seriously, clinical management of DM and its complications has caused a heavy burden on public health and global economies. $^{15}$

An effective glycaemic control significantly decreases the risk of DM complications and prevents its aggravation. ${ }^{67}$ Current evidences have shown that multiple factors like the age, socioeconomic status, duration of disease, medication usage, comorbidities, body mass index (BMI), family history, behaviour and lifestyle are closely linked with glycaemic control. ${ }^{8-10}$ As an important component of daily diet, the intake of fruits is restricted in patients with DM because of the sugar content. ${ }^{11}$ However, several studies have highlighted the role of fruit intake in controlling either haemoglobin Alc (HbAlc) or blood glucose. ${ }^{12}{ }^{13}$ Furthermore, a physically active lifestyle has been reported to improve insulin sensitivity and glycaemic control in either healthy population, people with impaired glucose tolerance of patients with DM. ${ }^{14-16}$ Additionally, aerobic and resistance training have been validated as effective exercises 
for controlling glycaemic in patients with type $2 \mathrm{DM}$ (T2DM). ${ }^{17}$

Previous studies have suggested that keeping a combined low-risk lifestyle more effectively prevents the development of DM. ${ }^{18}{ }^{19}$ We thereafter hypothesised that a proper intake of fresh fruits combined with sufficient physical activity may exert additional influences on glycaemic control compared with fresh fruit intake or physical activity alone. In the present study, we aim to investigate the joint association of fresh fruit intake and physical activity with glycaemic control in adult patients with DM.

\section{Research design and methods}

Study design and sampling

Data were collected from the 2017 Nanjing Chronic Disease and Risk Factor Surveillance (NCDRFS), which was a community-based cross-sectional study involving the regional representative population aged $\geq 18$ years. In this survey, a stratified, multistage probability cluster sampling design was adopted. Briefly, five districts (Qinhuai, Xuanwu, Gulou, Qixia and Luhe) were selected for cluster sampling according to the permanent population, geographical region and economic development status in the first stage. In the second and third stage, four subdistricts and three neighbourhood communities were selected for probability proportional to size sampling, respectively. In the fourth stage, 50 households within each neighbourhood community were randomly sampled. In the fifth stage, one person with minimal 18 years was randomly selected from each household using the Kish selection grid. Finally, samples were stratified according to the sex and age distribution in China, on the basis of Chinese population data in 2006. Those who have lived in the current residence for at least 18 months were eligible to participate in this study, and at last, a total of 5663 adult patients with DM (type 1 or type 2 ) were recruited.

\section{Data collection and measurement}

At each surveillance point, trained staff were responsible for face-to-face collecting data according to a standard protocol at local community health service centres/stations of the participants' registration address, including questionnaire survey, physical measurements and laboratory examination results.

Physical measurements included the weight, height and blood pressure. Blood samples were collected from all subjects in the morning after an overnight fasting for at least 10 hours. Laboratory examinations included the fasting plasma glucose (FPG) and four items of blood lipids, which were performed within 8 hours of receiving the samples. FPG was measured enzymatically using a glucose oxidase method.

\section{Variables}

\section{Dependent variables}

DM was defined as FPG $\geq 7.0 \mathrm{mmol} / \mathrm{L}$, or the use of hypoglycaemic agents, or any self-reported history of DM. ${ }^{20}$ Glycaemic control was defined as FPG $<7.0 \mathrm{mmol} / \mathrm{L}$ according to the laboratory testing of this survey.
Independent variables

Fresh fruit intake was classified as 'not eat', '1 99 g/day' and ' $\geq 100 \mathrm{~g} /$ day' based on the semiquantitative Food Frequency Questionnaire (FFQ), which was used to assess dietary intake during the previous year. The reliability and validity of the FFQ have been previously reported. ${ }^{21}$ 'Not eat' and '1 99 $\mathrm{g}$ /day' were defined as fresh fruit intake $<100 \mathrm{~g} /$ day. Physical activity was assessed by the Global Physical Activity Questionnaire, ${ }^{22}$ which was categorised into occupational, leisure time, transportation, household work and sedentary activities (eg, watching television, using a computer, playing video games and reading during leisure time). The frequency and duration of each domain were recorded. Physical activity level was classified as ' $<600$ MET-min/week' and ' $\geq 600$ MET$\mathrm{min} /$ week'. Insufficient physical activity was defined as physical activity $<600$ MET-min/week. ${ }^{23}$

\section{Covariates}

BMI was calculated using the formula: $B M I=\mathrm{kg} / \mathrm{m}^{2}$, where $\mathrm{kg}$ is a person's weight in kilograms and $\mathrm{m}^{2}$ is the height in metres squared. BMI $=18.5-23.9 \mathrm{~kg} / \mathrm{m}^{2},<18.5$ $\mathrm{kg} / \mathrm{m}^{2}, \geq 24.0 \mathrm{~kg} / \mathrm{m}^{2}$ indicates the normal weight, low weight, overweight and obesity, respectively. ${ }^{24}$ Current smoking was defined as smoking for 100 cigarettes in one's lifetime and currently smoking cigarettes. Current drinking was defined as alcohol intake for more than once per month during the past 12 months. ${ }^{25}$ The education level was grouped based on the highest education level of primary school and lower, middle/high school and college and higher. Family history of DM was defined as the first-degree relatives with DM, including the father, mother, siblings and offspring. ${ }^{26}$ Antidiabetic treatment depended on whether patients take antidiabetic medications regularly or irregularly.

The survey used to collect data in this study was presented in online supplemental table 1 .

\section{Quality control}

A vigorous quality control was implemented by Nanjing Municipal Center for Disease Control and Prevention (Nanjing CDC) to ensure the reliability of data, which was conducted throughout the survey period, including design and revision of the preliminary plan, unifying investigation tools, preparation of standard training materials and technical requirements, field supervision, technical guidance and data analysis. A total of $10 \%$ of questionnaires were collected for verification and 5\% of respondents were selected to review their physical measurements at each surveillance point. The feedback and correction were timely performed if there was any problem during quality control. All investigators were asked to participate in a uniform training programme and those passed the examination were qualified in this study. A manual of procedures was distributed by Nanjing CDC, and detailed instructions for administration of the questionnaires, anthropometric measurements and 
biological specimen collection were provided. All data were cross-checked.

\section{Statistical analysis}

Participant characteristics were expressed as counts and percentages and they were stratified by fresh fruit intake and physical activity level. In order to avoid the clustering of data, a generalised linear mixed model (GLMM) was introduced for analysis. First, a two-level logistic regression model without explanatory variables was fitted, and the variance of level 2 was calculated to determine the high-level group aggregation effect. If it existed, a twolevel logistic regression model with the participant and the corresponding community health service centre as the first and second level, respectively, was fitted. The adjusted model reported the results of GLMM after adjusting potential confounders (eg, sex, age, education level, smoking status, alcohol consumption, BMI, family history of DM and antidiabetic treatment) as previously reported. ${ }^{8-10}$ The multicollinearity in this model was tested. The relative risk was estimated by calculating the OR and corresponding 95\% CI.

Data entry and management were performed using EpiData software, V.3.1. All statistical analyses were conducted using the SPSS system (V.20; IBM). A twotailed $\mathrm{p}$ value $<0.05$ considered as statistically significant.

\section{Patient and public involvement}

No patients or public groups were involved in the conception, design and performance of this study.

\section{RESULTS}

A total of 5663 adult patients with DM completed the survey and examination. Classified by fresh fruit intake, there were $15.2 \%, 59.5 \%$ and $25.3 \%$ of cases as 'not eat', '1 99 g/day' and ' $\geq 100 \mathrm{~g} /$ day', respectively. Patients who did not take fresh fruit were more likely to maintain a normal weight compared with those with fresh fruit intake. Patients with fresh fruit intake $\geq 100 \mathrm{~g} /$ day were younger and more likely to have a family history of DM. Besides, patients with fresh fruit intake $\geq 100 \mathrm{~g}$ /day were more likely to achieve glycaemic control than those without fresh fruit intake or fresh fruit intake of 1 99 $\mathrm{g}$ /day and $54.9 \%$ of them maintained a physical activity level <600 MET-min/week. Insufficient physical activity was more likely to be reported in women, elderly over 60 years, those with lower education level, current smokers and those with poorer glycaemic control (table 1).

It is shown that the proportion of adult patients with DM achieving glycaemic control remained the lowest in those with fresh fruit intake $<100 \mathrm{~g} /$ day and physical activity level $<600$ MET-min/week, which was the highest in those with both fresh fruit intake $\geq 100 \mathrm{~g} /$ day and physical activity level $\geq 600 \mathrm{MET}-\mathrm{min} /$ week (figure 1).

We further analysed the correlation between fresh fruit intake and glycaemic control in adult patients with DM. After adjusting the sex, age, education level, smoking status, alcohol consumption, BMI, family history of DM and antidiabetic treatment, the greatest likelihood of glycaemic control was detected in patients with fresh fruit intake $\geq 100 \mathrm{~g} /$ day. Compared with those who did not take fresh fruit, patients with fresh fruit intake $\geq 100 \mathrm{~g} /$ day presented a higher odds of glycaemic control (OR: 1.512, 95\% CI: 1.236 to 1.851$)$. However, no significant difference in glycaemic control was detected between those without fresh fruit intake group and fresh fruit intake of $1 \sim 99 \mathrm{~g} /$ day (table 2). Based on this finding, adult patients with DM without fresh fruit intake and fresh fruit intake of $1 \sim 99 \mathrm{~g} /$ day were classified into one group as fresh fruit intake $<100 \mathrm{~g} /$ day.

The correlation of fresh fruit intake $(<100 \mathrm{~g} /$ day vs $\geq 100 \mathrm{~g}$ /day) or physical activity level ( $<600$ MET-min/ week vs $\geq 600$ MET-min/week) with glycaemic control in adult patients with DM was respectively assessed. After adjusting the sex, age, education level, smoking status, alcohol consumption, BMI, family history of DM and antidiabetic treatment, the likelihood of glycaemic control was $37.8 \%$ lower in patients with fresh fruit intake $<100$ $\mathrm{g}$ /day than those with fresh fruit intake $\geq 100 \mathrm{~g} /$ day, which was $26 \%$ higher in patients with physical activity level $\geq 600$ MET-min/week than those with $<600$ MET$\mathrm{min} /$ week (table 3).

Subsequently, the joint association of fresh fruit intake and physical activity with glycaemic control was identified. Compared with those with fresh fruit intake $<100 \mathrm{~g} /$ day and insufficient physical activity, odds of glycaemic control was higher in adult patients with DM with both fresh fruit intake $\geq 100 \mathrm{~g} /$ day and insufficient physical activity (OR: $1.468 ; 95 \%$ CI: 1.220 to 1.768 ), and those with both fresh fruit intake $<100 \mathrm{~g}$ /day and sufficient physical activity (OR: 1.435; 95\% CI: 1.256 to 1.639 ), while odds of glycaemic control was $75.8 \%$ higher in adult patients with DM with both fresh fruit intake $\geq 100$ $\mathrm{g} /$ day and sufficient physical activity (OR: $1.758 ; 95 \%$ CI: 1.471 to 2.102 ) (table 4 ).

\section{DISCUSSION}

Through analysing the representative sample from 2017 NCDRFS, it is found that fresh fruit intake $\geq 100 \mathrm{~g} /$ day and sufficient physical activity alone or in combination significantly enhanced the likelihood of glycaemic control in adult patients with DM, suggesting that less fresh fruit intake combined with insufficient physical activity might be a high risk for poor glycaemic control.

Previous studies have reported multiple factors for glycaemic control in patients with DM, including the socioeconomic status, family history of DM, medication, obesity, dietary intake and physical activity. ${ }^{8-10}$ As an important component of daily diet, fruit is rich in fibre and bioactive substances. ${ }^{27-29}$ Nevertheless, fruit has been considered as an unfavourable factor for glycaemic control in patients with DM due to the high content of sugar. ${ }^{11}$ Inconsistently, previous studies have shown that a sufficient intake of fresh fruit is able to reduce the risk 
Table 1 Baseline characteristics of 5663 adult patients with DM classified by fresh fruit intake and physical activity level

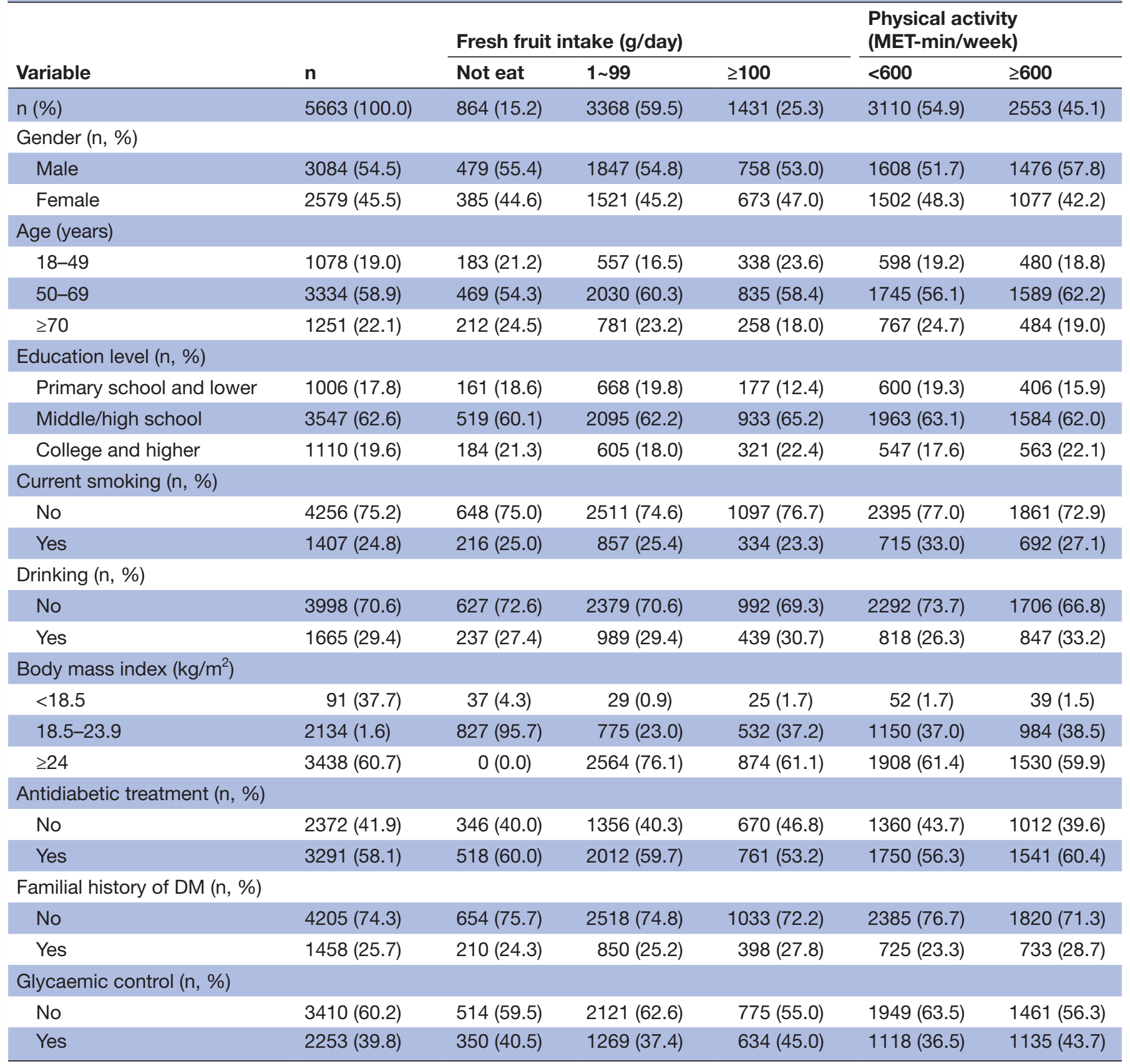

DM, diabetes mellitus.

of cardiovascular disease, ${ }^{30} 31$ some types of cancers ${ }^{32}$ and DM. ${ }^{33}{ }^{34}$ Allan et $a l^{13}$ reported that there are no significant differences in glycaemic control, body weight and waist circumference between subjects with two pieces of fresh fruit per day and those with less fruit intake. In the present study, we consistently found that there was no significant difference in glycaemic control between adult patients with DM who did not eat fresh fruit and those with fresh fruit intake of 1 99 g/day. Moreover, adult patients with $\mathrm{DM}$ with fresh fruit intake $\geq 100 \mathrm{~g} /$ day presented $37.8 \%$ higher likelihood of glycaemic control than those with fresh fruit intake $<100 \mathrm{~g} /$ day, which was consistent with previous findings. ${ }^{35} 36$ Fresh fruit intake is favourable to glycaemic control due to the beneficial compounds like fibre, which contribute to enhance insulin sensitivity, delay the absorption of carbohydrates and inhibit the postprandial glucose load. In addition, abundant polyphenols in fruit fight against the oxidative stress that impairs the glucose uptake by cells. ${ }^{34}$ Importantly, an effective glycaemic control is beneficial to decrease the risk of diabetic complications ${ }^{78}$ like carotid atherosclerosis, ${ }^{37}$ diabetic vascular complications ${ }^{38}$ and diabetic retinopathy. ${ }^{39}$ 


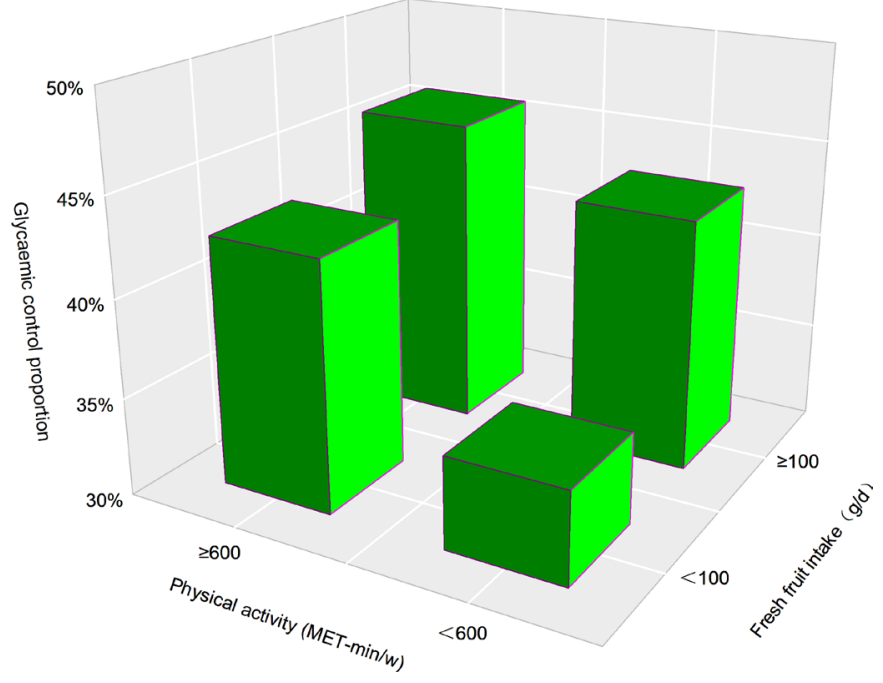

Figure 1 Joint association of fresh fruit intake and physical activity with the proportions of glycaemic control in adult patients with diabetes mellitus.

An adequate physical activity is good for enhancing insulin sensitivity, optimising BMI, and maintaining lipid metabolism, cardiorespiratory fitness and psychosocial well-being. ${ }^{16}$ A growing number of epidemiological studies have shown the correlation between physical activity and glycaemic control, the former of which is often recommended for patients with DM. ${ }^{14} 1617204041$ Based on the data collected by the Global Physical Activity Questionnaire, our results revealed that the likelihood of glycaemic control was $26 \%$ higher in adult patients with DM with physical activity level $\geq 600$ MET-min/week than those with $<600$ MET-min/week. Although the exact mechanism underlying physical activity in glycaemic control has not been fully elucidated, many randomised controlled trials (RCTs) supported the role of exercise in effectively regulating the glycolipid metabolism disorder of patients with DM. ${ }^{42}$ Moreover, a regular exercise can significantly strengthen the ability of skeletal muscles to increase glucose uptake and transport via upregulating GLUT-4 protein in skeletal muscle cells. ${ }^{43}$ A recent study emphasised that exercise intensity, volume and frequency are closely associated with the reduction of $\mathrm{HbAlc}$, and physiological adaptations following a long-term regular exercise training contribute to maintain the effective glycaemic control and insulin sensitivity. ${ }^{17}$ Hordern $e t a l^{41}$ suggested that the moderate-intensity aerobic physical

Table 2 OR $(95 \% \mathrm{Cl})$ of glycaemic control in 5663 adult patients with diabetes mellitus classified by fresh fruit intake

\begin{tabular}{lll}
\hline & OR & $\mathbf{9 5 \%} \mathbf{~ C l}$ \\
\hline $\begin{array}{lll}\text { Fresh fruit intake }(\mathrm{g} / \text { day }) \\
\text { Not eat }\end{array}$ & & \\
$\sim 100$ & 1.000 & \\
$\geq 100$ & 1.067 & 0.880 to 1.292 \\
\hline
\end{tabular}

Table 3 OR $(95 \% \mathrm{Cl})$ of glycaemic control in 5663 adult patients with diabetes mellitus classified by fresh fruit intake and physical activity level

\begin{tabular}{lll}
\hline & OR & $\mathbf{9 5 \%} \mathbf{~ C l}$ \\
\hline $\begin{array}{ll}\text { Fresh fruit intake (g/day) } \\
<100\end{array}$ & 1.000 & \\
$\geq 100$ & 1.378 & 1.209 to 1.571 \\
Physical activity (MET-min/week) & & \\
$<600$ & 1.000 & \\
$\geq 600$ & 1.260 & 1.124 to 1.412 \\
\hline
\end{tabular}

activity is conductive to maintain an ideal glycaemic control in patients with DM.

A growing number of studies have demonstrated that fresh fruit intake and physical activity significantly influence the primary, secondary and tertiary prevention of DM. ${ }^{17333641}$ Very latest, the combination of physical activity and healthy diet has been highlighted to enhance the likelihood of alleviating metabolic disorders. ${ }^{184}$ Theodora $e t$ $a l^{44}$ considered that exercise alone is less effective than a combination of exercise and diet control on decreasing the incidence of DM. But for those who have already diagnosed as DM, the combined effect of fresh fruit intake and physical activity on glycaemic control has not been reported yet. Our study for the first time identified that sufficient fresh fruit intake and physical activity synergistically exerted the active effect on glycaemic control in adult patients with DM. Either fresh fruit intake $\geq 100 \mathrm{~g}$ / day $(46.8 \%)$ or sufficient physical activity $(43.5 \%)$ was independently correlated with the increased likelihood of glycaemic control in adult patients with DM, and notably, their combination resulted in a $75.8 \%$ higher likelihood of glycaemic control. Therefore, it is of great significance for adult patients with DM to maintain fresh fruits intake $\geq 100 \mathrm{~g}$ /day and at the same time, avoiding bad habits of insufficient physical activity, thus achieving an ideal glycaemic control.

In the present study, we highlighted the high-quality analysis of population-based representative data using the GLMM to avoid the clustering of data. However, some limitations should be noted. First of all, glycaemic

Table 4 Joint association of fresh fruit intake and physical activity with the likelihood of glycaemic control in adult patients with diabetes mellitus

\begin{tabular}{lll} 
& OR & $95 \% \mathbf{~ C l}$ \\
\hline $\begin{array}{l}\text { Fresh fruit intake }<100 \mathrm{~g} / \text { day } \\
\text { and insufficient physical activity }\end{array}$ & 1.000 & \\
$\begin{array}{l}\text { Fresh fruit intake } \geq 100 \mathrm{~g} / \text { day } \\
\text { and insufficient physical activity }\end{array}$ & 1.468 & 1.220 to 1.768 \\
$\begin{array}{l}\text { Fresh fruit intake }<100 \mathrm{~g} / \text { day } \\
\text { and sufficient physical activity }\end{array}$ & 1.435 & 1.256 to 1.639 \\
$\begin{array}{l}\text { Fresh fruit intake } \geq 100 \text { g/day } \\
\text { and sufficient physical activity }\end{array}$ & 1.758 & 1.471 to 2.102 \\
\hline
\end{tabular}


control was assessed only by FPG, rather than the combination of HbAlc, and the duration of DM was not taken into consideration. Second, we fail to assess the volume and frequency of physical activity in adult patients with DM. Finally, our study was performed based on a crosssectional study, and the causality should be further validated.

\section{CONCLUSIONS}

Fresh fruit intake $\geq 100 \mathrm{~g}$ /day combined with sufficient physical activity was significantly associated with the high likelihood of glycaemic control in adult patients with DM. Considering their synergistic effect, we recommended that sufficient fresh fruit intake combined with physical activity should be adopted as the self-management approach to maintain glycaemic control in adult patients with DM. Large-scale RCTs are still needed in the future to validate our findings, and it is also necessary to identify the potential influence of the volume and frequency of physical activity on glycaemic control in adult patients with DM.

Acknowledgements We are grateful to all the dedicated fieldworkers who have been involved in the surveys and all participants who have facilitated the survey implementation at each community.

Contributors JW, XH and NZ contributed to study design, data collection and analysis and manuscript drafting; $\mathrm{CW}, \mathrm{SQ}, \mathrm{QY}, \mathrm{ZQ}, \mathrm{HZ}, \mathrm{CL}$ and $\mathrm{WW}$ were responsible for data collection and manuscript revision; NZ supervised the research and had the primary responsibility for final content. And NZ acted as guarantor for the overall content of the article. All the authors read and approved the final manuscript.

This research work was funded by the Nanjing Municipal Medical Science and Technique Development Foundation, grant number ZKX18049.

Competing interests None.

Patient consent for publication Not applicable.

Ethics approval This study involves human participants and was approved by Ethics Committee: Nanjing Municipal Center for Disease Control and Prevention ID: PJ2017002. Participants gave informed consent to participate in the study before taking part.

Provenance and peer review Not commissioned; externally peer reviewed.

Data availability statement Data are available upon reasonable request. Not applicable.

Supplemental material This content has been supplied by the author(s). It has not been vetted by BMJ Publishing Group Limited (BMJ) and may not have been peer-reviewed. Any opinions or recommendations discussed are solely those of the author(s) and are not endorsed by BMJ. BMJ disclaims all liability and responsibility arising from any reliance placed on the content. Where the content includes any translated material, BMJ does not warrant the accuracy and reliability of the translations (including but not limited to local regulations, clinical guidelines, terminology, drug names and drug dosages), and is not responsible for any error and/or omissions arising from translation and adaptation or otherwise.

Open access This is an open access article distributed in accordance with the Creative Commons Attribution Non Commercial (CC BY-NC 4.0) license, which permits others to distribute, remix, adapt, build upon this work non-commercially, and license their derivative works on different terms, provided the original work is properly cited, appropriate credit is given, any changes made indicated, and the use is non-commercial. See: http://creativecommons.org/licenses/by-nc/4.0/.

\section{ORCID iDs}

Jie Wu http://orcid.org/0000-0002-5735-4227

Xin Hong http://orcid.org/0000-0003-0927-5484

Nan Zhou http://orcid.org/0000-0002-3111-3548
REFERENCES

1 International Diabetes Federation. IDF Diabetes Atlas [Internet]. 9th ed, 2019. http://www.diabetesatlas.org

2 Vos T, Barber RM, Bell B, et al. Global, regional, and national incidence, prevalence, and years lived with disability for 301 acute and chronic diseases and injuries in 188 countries, 1990-2013: a systematic analysis for the global burden of disease study 2013 . The Lancet 2015;386:743-800.

3 Barr ELM, Zimmet PZ, Welborn TA, et al. Risk of cardiovascular and all-cause mortality in individuals with diabetes mellitus, impaired fasting glucose, and impaired glucose tolerance: the Australian diabetes, obesity, and lifestyle study (AusDiab). Circulation 2007;116:151-7.

4 Yau JWY, Rogers SL, Kawasaki R, et al. Global prevalence and major risk factors of diabetic retinopathy. Diabetes Care 2012;35:556-64.

5 Wang Q, Zhang X, Fang L, et al. Prevalence, awareness, treatment and control of diabetes mellitus among middle-aged and elderly people in a rural Chinese population: a cross-sectional study. PLoS One 2018;13:e0198343.

6 UK Prospective Diabetes Study (UKPDS) Group. Intensive bloodglucose control with sulphonylureas or insulin compared with conventional treatment and risk of complications in patients with type 2 diabetes (UKPDS 33). The Lancet 1998;352:837-53.

7 Marso SP, Bain SC, Consoli A, et al. Semaglutide and cardiovascular outcomes in patients with type 2 diabetes. $N$ Engl $\mathrm{J}$ Med 2016;375:1834-44

8 Cheng LJ, Wang W, Lim ST, et al. Factors associated with glycaemic control in patients with diabetes mellitus: a systematic literature review. J Clin Nurs 2019;28:1433-50.

9 Wu M, Wen J, Qin Y, et al. Familial history of diabetes is associated with poor glycaemic control in type 2 diabetics: a cross-sectional study. Sci Rep 2017;7:1432-7.

10 Pai L-W, Chang P-Y, Chen W, Lee WP, Pi-Ying Chang PY, Wei $\mathrm{C}$, et al. The effectiveness of physical leisure time activities on glycaemic control in adult patients with diabetes type 2: a systematic review. JBI Libr Syst Rev 2012;10:1-20.

11 You SG, Gao Y, Yang XS. Survey on improper awareness of diet in patient with type 2 diabetes. J Prev Med Inf 2015;31:436-8.

12 Sargeant LA, Khaw KT, Bingham S, et al. Fruit and vegetable intake and population glycosylated haemoglobin levels: the EPIC-Norfolk study. Eur J Clin Nutr 2001;55:342-8.

13 Christensen AS, Viggers L, Hasselström K, Allan C, Lone V, Kjeld H, et al. Effect of fruit restriction on glycemic control in patients with type 2 diabetes--a randomized trial. Nutr J 2013;12:29.

14 Riddell M, Perkins BA. Exercise and glucose metabolism in persons with diabetes mellitus: perspectives on the role for continuous glucose monitoring. J Diabetes Sci Technol 2009;3:914-23.

15 Glans F, Eriksson K-F, Segerström A, et al. Evaluation of the effects of exercise on insulin sensitivity in Arabian and Swedish women with type 2 diabetes. Diabetes Res Clin Pract 2009;85:69-74.

16 Yang D, Yang Y, Li Y, et al. Physical exercise as therapy for type 2 diabetes mellitus: from mechanism to orientation. Ann Nutr Metab 2019;74:313-21.

17 Kirwan JP, Sacks J, Nieuwoudt S. The essential role of exercise in the management of type 2 diabetes. Cleve Clin J Med 2017;84:S15-21.

18 Catherine AE, Michael JH. Combined diet and physical activity is better than diet or physical activity alone at improving health outcomes for patients in New Zealand's primary care intervention. BMC Public Health 2018;18:230.

19 Qian X, Liu X, Mao Z, et al. Fruit and vegetable intake modifies the associations between suppressor of cytokine signaling 3 genetic variants and type 2 diabetes. Eur J Nutr 2020;59:3441-9.

20 Chinese Diabetes Society. Chinese guidelines for type 2 diabetes mellitus. Chin J Diabetes Mellitus 20172018;10:4-67.

21 Ye Q, Hong X, Wang Z, et al. Reproducibility and validity of an FFQ developed for adults in Nanjing, China. Br J Nutr 2016;115:887-94

22 IPAQ group. International physical activity questionnaire [EB/OL], 2002. Available: http : //www.ipaq.ki.se/downloads.html

23 Fan M, Lyu J, He P. [Chinese guidelines for data processing and analysis concerning the International Physical Activity Questionnaire]. Zhonghua Liu Xing Bing Xue Za Zhi 2014;35:961-4.

24 Department of Disease Control,Ministry of Health of the People's Republic of China. The guidelines for prevention and control of overweight and obesity in Chinese adults. Beijing: People's Medical Publishing House, 2006.

$25 \mathrm{Xu} \mathrm{Y,} \mathrm{Wang} \mathrm{L,} \mathrm{He} \mathrm{J,} \mathrm{et} \mathrm{al.} \mathrm{Prevalence} \mathrm{and} \mathrm{control} \mathrm{of} \mathrm{diabetes} \mathrm{in}$ Chinese adults. JAMA 2013;310:948-58.

26 Zhang Y, Chen $\mathrm{H}$, Lu H, et al. Prevalence and risk of diabetes based on family history in the Shanghai high-risk diabetic screen (SHiDS) study. Diabet Med 2016;33:1705-11. 
27 González-Gallego J, García-Mediavilla MV, Sánchez-Campos S, et al. Fruit polyphenols, immunity and inflammation. Br J Nutr 2010;104 Suppl 3:S15-27.

28 Chong MF-F, Macdonald R, Lovegrove JA. Fruit polyphenols and CVD risk: a review of human intervention studies. Br J Nutr 2010;104 Suppl 3:S28-39.

29 Feeney MJ. Fruits and the prevention of lifestyle-related diseases. Clin Exp Pharmacol Physiol 2004;31 Suppl 2:S11-13.

30 Dauchet L, Amouyel P, Hercberg S, et al. Fruit and vegetable consumption and risk of coronary heart disease: a meta-analysis of cohort studies. J Nutr 2006;136:2588-93.

31 Martínez-González MA, Lamuela-Raventos RM. The unparalleled benefits of fruit. Br J Nutr 2009;102:947-8.

32 Aune D, Lau R, Chan DSM, et al. Nonlinear reduction in risk for colorectal cancer by fruit and vegetable intake based on meta-analysis of prospective studies. Gastroenterology 2011;141:106-18.

33 Muraki I, Imamura F, Manson JE, et al. Fruit consumption and risk of type 2 diabetes: results from three prospective longitudinal cohort studies. BMJ 2013;347:f5001.

34 Li S, Miao S, Huang Y, et al. Fruit intake decreases risk of incident type 2 diabetes: an updated meta-analysis. Endocrine 2015;48:454-60.

35 Su J, Qin Y, Pan XQ, Jian S, Yu Q, Xiaoqun P, et al. [Association between fresh fruit consumption and glycemic control in patients with type 2 diabetes]. Zhonghua Liu Xing Bing Xue Za Zhi 2019;40:660-5.
36 Hegde SV, Adhikari P, M N, et al. Effect of daily supplementation of fruits on oxidative stress indices and glycaemic status in type 2 diabetes mellitus. Complement Ther Clin Pract 2013;19:97-100.

37 Chan H-T, Yiu K-H, Wong C-Y, et al. Increased dietary fruit intake was associated with lower burden of carotid atherosclerosis in Chinese patients with type 2 diabetes mellitus. Diabet Med 2013;30:100-8.

$38 \mathrm{Du} \mathrm{H}$, Li L, Bennett D, et al. Fresh fruit consumption in relation to incident diabetes and diabetic vascular complications: a $7-y$ prospective study of 0.5 million Chinese adults. PLoS Med 2017;14:e1002279.

39 Tanaka S, Yoshimura Y, Kawasaki R, et al. Fruit intake and incident diabetic retinopathy with type 2 diabetes. Epidemiology 2013;24:204-11.

40 Boulé NG, Haddad E, Kenny GP, et al. Effects of exercise on glycemic control and body mass in type 2 diabetes mellitus: a metaanalysis of controlled clinical trials. JAMA 2001;286:1218-27.

41 Hordern MD, Cooney LM, Beller EM, et al. Determinants of changes in blood glucose response to short-term exercise training in patients with type 2 diabetes. Clin Sci 2008;115:273-81.

42 Thent ZC, Das S, Henry LJ. Role of exercise in the management of diabetes mellitus: the global scenario. PLoS One 2013;8:e80436.

43 Hussey SE, McGee SL, Garnham A, et al. Exercise increases skeletal muscle GLUT4 gene expression in patients with type 2 diabetes. Diabetes Obes Metab 2012;14:768-71.

44 Psaltopoulou T, Ilias I, Alevizaki M, Theodora P, loannis I, Maria A. The role of diet and lifestyle in primary, secondary, and tertiary diabetes prevention: a review of meta-analyses. Rev Diabet Stud 2010;7:26-35. 